\title{
Characteristics of Soil Nitrogen and Phosphorus in Different Types of Areas in the Pisha Sandstone Region
}

\section{xuefeng Li}

School of Soil and Water Conservation, Beijing Forestry University, Beijing 100083, PR China liangyi Rao ( $\square$ raoliangyi123@163.com )

School of Soil and Water Conservation, Beijing Forestry University, Beijing 100083, PR China yeqin $\mathrm{Xu}$

School of Soil and Water Conservation, Beijing Forestry University, Beijing 100083, PR China

\section{Research Article}

Keywords: Pisha sandstone, different typological areas, slope position, nitrogen, phosphorus.

Posted Date: October 28th, 2021

DOl: https://doi.org/10.21203/rs.3.rs-994889/v1

License: (1) This work is licensed under a Creative Commons Attribution 4.0 International License.

Read Full License 


\section{Abstract}

Little is known about the distribution of $\mathrm{N}$ and $\mathrm{P}$ in Pisha sandstone soils from different types of areas. In this study, three typical areas in this region, which included the Er Laohu small watershed (soil-covered area), the Tela small watershed (sand-covered area), and the Shibu Ertai small watershed (bare area), were chosen as experimental objects. A total of 27 soil sections were constructed (Took three parts in the upper, middle and lower of each watershed, respectively), and 486 soil samples were taken from different slope positions and slope directions. Bare Pisha sandstone had the highest mean TN concentration of $0.53 \mathrm{~g} / \mathrm{kg}$, which was about $45.06-45.30 \%$ higher than soil-covered and sand-covered Pisha sandstone. Sand-covered Pisha sandstone had a lower TP concentration of $37.93-40.62 \%$ than the bare $(5.04 \mathrm{~g} / \mathrm{kg})$ and soil-covered $(4.64 \mathrm{~g} / \mathrm{kg}$ ) Pisha sandstone. The concentration of AN in the bare Pisha sandstone was $23.98 \mathrm{mg} / \mathrm{kg}$, which was about 2.85-3.85 times higher than that in the sand-covered and soil-covered Pisha sandstone. Ni concentration in bare Pisha sandstone $(5.14 \mathrm{mg} / \mathrm{kg})$ was approximately 3-4 times higher compared to soil-covered and sand-covered Pisha sandstone. The AP concentration in soil-covered Pisha sandstone was $7.56 \mathrm{mg} / \mathrm{kg}$, which was about $68-72.21 \%$ higher than that in bare and sandcovered Pisha sandstone areas. Overarchingly, our results suggest that different Pisha sandstone types and slope positions significantly affect the spatial distribution of $\mathrm{N}$ and $\mathrm{P}$. That has created a greater obstacle for the local population to carry out agricultural activities in the Pisha sandstone region.

\section{Introduction}

Soil degradation and soil erosion on the Loess Plateau are becoming increasingly serious due to the impact of human production activities and climate change. As a result, there are serious threats to the ecological and habitat environment of the region ${ }^{1}$. Large amount of clastic bedrock sand-producing area in Loess Plateau is concentrated in Pisha sandstone area, and rough sediment from this area into the Yellow River accounts for $62 \%$ of the total sediment volume. Soil erosion in this area could reach $20000 \mathrm{t} / \mathrm{km}^{2} /$ year, which seriously affects the development and implementation of ecological civilization in the area ${ }^{2} ;{ }^{3}$. As part of China's 12th Five-Year Plan, integrated soil erosion management was initiated in 2013 in the Pisha sandstone areas. With the rapid development of vegetation restoration and integrated management in the Pisha sandstone area, it has become a hot spot for research on ecological restoration ${ }^{4-6}$.

The Pisha Sandstone, which is distributed in large quantities along the borders of Shanxi, Shaanxi, and Inner Mongolia in China, it has been described as suffering from "environmental cancer" ${ }^{\text {" }}$. Soils of Pisha sandstone are characterized by loose laminae, high permeability, low colloid concentration, and extreme barrenness ${ }^{8}$. In addition, high summer precipitation and low vegetation cover in this area mean that Pisha sandstone rock masses could easily collapse and turn into sand and soil. Intense erosion attributed to rainfall runoff has caused severe water and soil loss in the Pisha Sandstone region ${ }^{9}$. Soil-covered sandstone, sand-covered sandstone and bared sandstone are the three most representative types of Pisha sandstone in the area. Through research on the spatial distribution patterns of $\mathrm{N}$ and $\mathrm{P}$ in different 
types of zones, this paper aims to better understand the $\mathrm{N}$ and $\mathrm{P}$ distribution of soils in different types of Pisha sandstone. However, the same type of area was mainly concerned with the $\mathrm{N}$ and $\mathrm{P}$ distribution of soils on different slope directions and slope positions. It provides a theoretical basis for ecological restoration in the Pisha sandstone region of the country, and the process of restoring the ecological environment could be carried out with different restoration measures depending on the type of area. Previous research on the Pisha sandstone area has focused on lithological and morphological characteristics (including physical, chemical and mineralogical characteristics, etc.) ${ }^{8}$; ${ }^{10}$, soil erosion (including wind, water and gravity erosion mechanisms, etc.) 2 ; $6.7 ;{ }^{11-13}$, land use patterns (including wasteland, farmland, and scripture forest, etc.) ${ }^{14-16}$, and ecological restoration (including sea-buckthorn flexible dams, fish-scale pits planted with oleander and sprayed cementation on slopes, etc. ${ }^{5} ;{ }^{11 ;} ;{ }^{17}$, among other aspects. However, there were few investigations and analyses of the spatial distribution evolution of $\mathrm{N}$ and $\mathrm{P}$ in the Pisha sandstone area after erosion (slope direction and slope position) in China. Thus far, fewer domestic scholars have explored in detail the distribution patterns of soil $\mathrm{N}$ and $\mathrm{P}$ in different Pisha sandstones. Especially, there were less researches on the spatial distribution of $\mathrm{N}$ and $\mathrm{P}$ in Pisha sandstone under controlled soil conditions (soil-covered sandstone, sand-covered sandstone and bare sandstone) after erosion.

Since $\mathrm{N}$ and $\mathrm{P}$ are key trophic factors governing ecosystem productivity in the Pisha sandstone region, it would be of great ecological and environmental significance to research $\mathrm{N}$ and $\mathrm{P}$ stocks and storage potential ${ }^{18}$. In this research, a total of 243 points (486 samples) were sampled along the valley in different Pisha sandstone areas. We measured soil $\mathrm{N}$ and $\mathrm{P}$ concentrations within 0-20 cm depth at the sampling sites. To better understand the mechanisms of soil $\mathrm{N}$ and $\mathrm{P}$ variation in different Pisha sandstone regions. Our research objectives were (1) the effect of different Pisha sandstone soils on $\mathrm{N}$ and $\mathrm{P}$ levels, and (2) the effect of slope orientation and slope position on soil $\mathrm{N}$ and $\mathrm{P}$ levels in the same Pisha sandstone type area.

\section{Materials And Methods \\ 2.1. Study Area}

This study was conducted in Jungar Banner, Inner Mongolia of the Loess Plateau (Fig. 1, 39 $26^{\circ}-39^{\circ} 56^{\prime}$ $\mathrm{N}, 110^{\circ} 32^{\prime}-111^{\circ} 06^{\prime} \mathrm{E}$ ), which is dominated by temperate continental monsoon climates and four distinct seasons. The annual precipitation is highly variable $(250-400 \mathrm{~mm})$ and the annual temperature ranges from $6^{\circ} \mathrm{C}$ to $8^{\circ} \mathrm{C}$. In recent five years, the average annual rainfall has been $350 \mathrm{~mm}$. Summer (July to September) provides more than 80 percent of the annual rainfall. The Shibu Ertai, Er Laohu, and Tela small watersheds in Jungar Banner were selected for study, since they were representative of the bare, soil-covered, and sand-covered areas of the Pisha sandstone region, respectively. In the Shibu Ertai small watershed, the top soil layer at the slope crest was barren, with an average soil thickness of less than 30 $\mathrm{cm}$. Soil erosion was serious on the slope and the soil coverage rate was as low as more than $10 \%$. In the Er Laohu small watershed, the soil layer has an uneven thickness, and there was a large amount of 
exposed bedrock in the thin part of the slope soil and several meters of loess in the thick part. The slope of the undulating and broken terrain was generally $40^{\circ}$ to $60^{\circ}$ degrees, with a maximum of $90^{\circ}$. The average valley density in this basin was $7 \mathrm{~km} / \mathrm{km}^{2}$. In the Tela small watershed, some slopes were relatively gentle, ranging from $30^{\circ}$ to $50^{\circ}$, and the slopes were covered with sand and dust. Woody plant included Hippophae rhamnoides Linn., Caragana korshinskii, Rosa xanthina, Achnatherum splendens, and Hedysarum scoparium. Herbs plant included Astragalus adsurgens, Vicia sepium, and Ceratoides latens. Accumulated litter was scarce.

\subsection{Study design}

In this study, by comprehensively considering the geographical distribution, site conditions, soil conditions, vegetation density, comprehensive erosion control, and other factors, we chose the Shibu Ertai, Er Laohu, and Tela small watersheds to represent bare area, soil-covered area, and sand-covered area, respectively. Three soil cross-sections were taken in the upper, middle, and lower reaches of the three experimental areas, respectively. The "five-point sampling method" was adopted to sample in two layers $(0-10 \mathrm{~cm}$ and $10-20 \mathrm{~cm}$ ) on both of sunny (North-facing slopes) and shady (South-facing slopes) slopes on the slope top, upper slope, middle slope, lower slope and gully bottom. Similar habitat conditions were ensured among the sampling points. The total nitrogen (TN), ammonia nitrogen (AN), nitrate nitrogen (Ni), total phosphorus (TP), and ammonia phosphorus (AP) of the soil samples were measured separately. The data were then compared to determine the differences in soil characteristics among the three types of area, the different slope positions and directions.

\subsection{Collection and pretreatment of soil samples}

In May 2018, soil samples were collected in two layers $(0-10 \mathrm{~cm}$ and $10-20 \mathrm{~cm})$ at different slope positions and slope directions in each section of the Shibu Ertai, Er Laohu, and Tela watersheds. In this study, 3 sections were taken in the upper, middle, and lower reaches of each small watershed, and a total of 243 sites (486 samples) were sampled in 27 sections. After removing plant leaves, roots, insects, gravel, and other debris, $500 \mathrm{~g}$ of mixed soil samples were taken at five points that were systematically arranged in each layer and put into a cloth bag. The samples were separated by the quartering method; one sample was air-dried and sieved in order to determine the concentrations of soil nutrients, and the rest were sealed and stored. The concentrations of specific soil nutrients were determined using agrochemical analysis ${ }^{19}$ (Bao, 2000).

\subsection{Data processing}

The Excel 2010 and SPSS 22.0 statistical analysis soft wares (IBM, Armonk, NY, USA) were used for data processing and chart analysis, and one-way ANOVA was used to analyze the differences in soil nutrient concentration at different slope positions and slope directions.

\section{Results}




\subsection{Analysis of soil $\mathbf{N}$ and $\mathrm{P}$ concentration in different types of area}

$\mathrm{N}$ and $\mathrm{P}$ as essential chemical elements in plant growth and development played an important role in the process of material cycle. TN, AN, Ni, TP, and AP averaged in the range of $0.36-0.51 \mathrm{~g} / \mathrm{kg}, 6.23-23.98$ $\mathrm{mg} / \mathrm{kg}, 0.89-5.14 \mathrm{mg} / \mathrm{kg}, 2.88-4.85 \mathrm{~g} / \mathrm{kg}$, and $4.39-7.59 \mathrm{mg} / \mathrm{kg}$ for the Pisha sandstone, respectively (Table 1). Soil TN and TP coefficients of variation (CV) for the Pisha sandstone were moderate variability (Table 1). Coefficients of variation of soil TN and TP were $15.53 \%$ and $22.76 \%$ for bare Pisha sandstone, $29.65 \%$ and $30.19 \%$ for soil-covered Pisha sandstone, and $18.57 \%$ and $33.19 \%$ for sand-covered Pisha sandstone, respectively. Coefficients of variation for fast-acting nutrients of $\mathrm{N}$ and $\mathrm{P}$ in Pisha sandstone soils were small and basically of low to moderate variability. Variability ranges were $11.53-18.86 \%$, 8.99-18.18\%, and $13.14-27.09 \%$ for bare Pisha sandstone, soil-covered Pisha sandstone, and sandcovered Pisha sandstone, respectively (Table 1).

Table 1 Summary statistics for the soil nitrogen and soil phosphorus levels at the different types of area. 


\begin{tabular}{|c|c|c|c|c|c|c|}
\hline Area type & Indicator & MIN & MAX & MEAN & $S D$ & CV (\%) \\
\hline \multirow[t]{5}{*}{ Bare area } & $\mathrm{TN}(\mathrm{g} / \mathrm{kg})$ & 0.38 & 0.79 & 0.51 & 0.12 & 22.76 \\
\hline & AN (mg/kg) & 17.15 & 29.54 & 23.98 & 2.76 & 11.53 \\
\hline & $\mathrm{Ni}(\mathrm{mg} / \mathrm{kg})$ & 3.98 & 5.92 & 5.14 & 0.63 & 12.21 \\
\hline & $\mathrm{TP}(\mathrm{g} / \mathrm{kg})$ & 3.75 & 6.42 & 4.85 & 0.75 & 15.53 \\
\hline & AP (mg/kg) & 3.29 & 6.28 & 4.50 & 0.84 & 18.66 \\
\hline \multirow[t]{5}{*}{ Soil-covered area } & $\mathrm{TN}(\mathrm{g} / \mathrm{kg})$ & 0.22 & 0.56 & 0.37 & 0.11 & 29.65 \\
\hline & AN (mg/kg) & 13.26 & 19.46 & 16.82 & 1.51 & 8.99 \\
\hline & $\mathrm{Ni}(\mathrm{mg} / \mathrm{kg})$ & 0.89 & 1.60 & 1.19 & 0.22 & 18.18 \\
\hline & $\mathrm{TP}(\mathrm{g} / \mathrm{kg})$ & 2.73 & 6.85 & 4.64 & 1.40 & 30.19 \\
\hline & AP (mg/kg) & 5.98 & 8.73 & 7.56 & 0.76 & 10.09 \\
\hline \multirow[t]{5}{*}{ Sand-covered area } & $\mathrm{TN}(\mathrm{g} / \mathrm{kg})$ & 0.19 & 0.67 & 0.36 & 0.12 & 33.39 \\
\hline & AN (mg/kg) & 4.33 & 7.50 & 6.23 & 0.95 & 15.22 \\
\hline & $\mathrm{Ni}(\mathrm{mg} / \mathrm{kg})$ & 0.70 & 1.10 & 0.89 & 0.12 & 13.14 \\
\hline & $\mathrm{TP}(\mathrm{g} / \mathrm{kg})$ & 1.70 & 3.53 & 2.88 & 0.53 & 18.57 \\
\hline & $\mathrm{AP}(\mathrm{mg} / \mathrm{kg})$ & 2.66 & 6.46 & 4.39 & 1.19 & 27.09 \\
\hline
\end{tabular}

\subsection{Characterization of TN and TP concentrations in different Pisha sandstones}

TN concentration of bare Pisha sandstone was significantly different compared with soil-covered Pisha sandstone and sand-covered Pisha sandstone $(\mathrm{p}<0.05)$. No significant effect of soil depth $(0-20 \mathrm{~cm})$ on the concentration of TN and TP was observed in the Pisha sandstone area (Fig. 2). Bare Pisha sandstone has the highest average TN concentration of $0.53 \mathrm{~g} / \mathrm{kg}$ which was approximately $45.30 \%$ higher than soilcovered Pisha sandstone and $45.06 \%$ higher than sand-covered Pisha sandstone. There were no significant differences in the mean TN concentration of the soil-covered Pisha sandstone compared to the sand-covered Pisha sandstone.; Sand-covered Pisha sandstone had the lowest TP concentration of only $2.88 \mathrm{~g} / \mathrm{kg}$, which was significantly different compared to bare Pisha sandstone and soil-covered Pisha sandstone $(p<0.05)$. TP concentration of sand-covered Pisha sandstone was $40.62 \%$ lower than that of bare Pisha sandstone $(5.04 \mathrm{~g} / \mathrm{kg}$ ) and $37.93 \%$ lower than that of soil-covered Pisha sandstone 
$(4.64 \mathrm{~g} / \mathrm{kg})$. There were no significant differences in the mean TP concentration of the bare Pisha sandstone compared to the soil-covered Pisha sandstone.

There were partially significant differences in the TN and TP concentrations of slopes of the same type of Pisha sandstone $(p<0.05)$. It was most obvious that the TN and TP concentrations at the bottom of the slope were significantly higher than those on the slope surface in the same-type Pisha sandstone. However, the variations of TN and TP concentrations among different slope positions on the slope were not obvious (Fig. 2).

\subsection{Analysis of effective $\mathbf{N}$ concentration in different Pisha sandstone types of soils.}

Bare Pisha sandstone soils had the highest available nitrogen (AN, Ni) concentrations, which were significantly different $(P<0.05)$ from soil-covered Pisha sandstone and sand-covered Pisha sandstone. AN concentration of $23.98 \mathrm{mg} / \mathrm{kg}$ in bare Pisha sandstone was about 2.85 times higher than that in sandcovered Pisha sandstone areas. AN concentration of $6.23 \mathrm{mg} / \mathrm{kg}$ for sand-covered Pisha sandstone occupied only $37.04 \%$ of the soil-covered Pisha sandstone (Fig. 3). Ni concentration in bare Pisha sandstone $(5.14 \mathrm{mg} / \mathrm{kg})$ was approximately 3-4 times higher compared to soil-covered Pisha sandstone and sand-covered Pisha sandstone. Ni concentration of $1.19 \mathrm{mg} / \mathrm{kg}$ in soil-covered Pisha sandstone was about $33.71 \%$ higher than that in sand-covered Pisha sandstone area (Fig. 3). Available nitrogen (AN, Ni) concentrations under the same slope position in different Pisha sandstones also differed significantly, with the highest concentration in the bare Pisha sandstone and the lowest in the sand-covered Pisha sandstone $(P<0.05)$.

Significant differences in available nitrogen (AN, Ni) concentrations were found at different slope locations for the same type of Pisha sandstone, all of which showed significantly higher concentrations near the top of the slope than near the bottom $(p<0.05)$. The AN concentration level on the shaded upper slope of the bare Pisha sandstone was $26.46 \mathrm{mg} / \mathrm{kg}$, which was $25.90 \%$ higher than that on the slope bottom. Meanwhile, the Ni concentration level at the slope bottom was $4.01 \mathrm{mg} / \mathrm{kg}$, which was significantly lower than that at the slope top on the sunny side (31.26\% lower); Available nitrogen ( $\mathrm{AN}, \mathrm{Ni})$ concentration levels were highest at the shaded slope top in the soil-covered Pisha sandstone area, with AN of $18.86 \mathrm{mg} / \mathrm{kg}$ being $33.57 \%$ higher than that at the slope bottom. At the same time the $\mathrm{Ni}$ concentration level at the slope bottom $(0.90 \mathrm{mg} / \mathrm{kg})$ was $35.87 \%$ lower than that at the shaded slope top. In the sand-covered Pisha sandstone area, the highest AN level was found on the shaded upper slope near the top position $(7.28 \mathrm{mg} / \mathrm{kg}$ ) which was $65.01 \%$ higher than the bottom of the slope. $\mathrm{Ni}$ concentration levels at the shaded slope top were $52.05 \%$ higher compared to the slope bottom (0.70 $\mathrm{mg} / \mathrm{kg}$ ). This indicates that in the Pisha sandstone area, the available nitrogen (AN, Ni) of the soil was significantly influenced by the Pisha sandstone type and slope positions $(p<0.05)$. 


\subsection{Analysis of soil AP concentration at different slope positions and slope directions in different types of area}

The highest available phosphorus (AP) concentration was found in the soil-covered Pisha sandstone, which was significantly different $(P<0.05)$ from the bare Pisha sandstone and sand-covered Pisha sandstone. The AP concentration of $7.56 \mathrm{mg} / \mathrm{kg}$ for soil-covered Pisha sandstone was about $68 \%$ higher than that of the bare Pisha sandstone area and about $72.21 \%$ higher than that of the sand-covered Pisha sandstone area (Fig. 4). The AP concentrations on the same slope positions were also significantly different in the different Pisha sandstone areas, with the soil-covered Pisha sandstone being significantly higher than the other two areas $(p<0.05)$.

Significant differences in AP concentrations were found in different slope positions of the same type of Pisha sandstone, all of which showed significantly higher concentrations in zones near the top of the slope than in zones near the bottom $(p<0.05)$. Bare Pisha sandstone AP concentrations ranged from 3.33 $\sim 6.11 \mathrm{mg} / \mathrm{kg}$, and the highest AP concentration was about $83.49 \%$ higher at the shaded slope top compared to the slope bottom. The AP concentration in the soil-covered Pisha sandstone ranged from 6.29 to $8.63 \mathrm{mg} / \mathrm{kg}$, with the lowest AP concentration at the bottom of the slope. It was $37.21 \%$ and $36.97 \%$ higher at the two ends of the (shaded and sunny) slope tops than at the slope bottoms, respectively. The AP concentrations of sand-covered Pisha sandstone ranged from 2.86 to $6.09 \mathrm{mg} / \mathrm{kg}$.

The AP concentration at the bottom slope was only $2.86 \mathrm{mg} / \mathrm{kg}$, which was $53.06 \%$ and $51.08 \%$ lower than that at the top of both ends (shaded and sunny) slopes, respectively (Fig. 4). This indicates that in the Pisha sandstone area, the AP of the soil is significantly influenced by the type of Pisha sandstone and the slope positions $(p<0.05)$.

\section{Discussion}

Soil is the basis of the growth and development of terrestrial plants, which elements such as $\mathrm{N}$ and $\mathrm{P}$ in the soil play an extremely important role in the process of plant growth, material circulation, and energy conversion in terrestrial ecosystem.

\subsection{Analysis of soil characteristics of different Pisha sandstones}

In this study, we found that the average soil concentrations of TN, AN, Ni, TP, and AP in shallow soil (0-20 $\mathrm{cm}$ ) of the bare area were $0.51 \mathrm{~g} / \mathrm{kg}, 23.98 \mathrm{mg} / \mathrm{kg}, 5.14 \mathrm{mg} / \mathrm{kg}, 4.85 \mathrm{~g} / \mathrm{kg}$, and $4.50 \mathrm{mg} / \mathrm{kg}$, respectively. The average concentrations in a soil-covered area were $0.37 \mathrm{~g} / \mathrm{kg}, 16.82 \mathrm{mg} / \mathrm{kg}, 1.19 \mathrm{mg} / \mathrm{kg}, 4.64 \mathrm{~g} / \mathrm{kg}$, and $7.56 \mathrm{mg} / \mathrm{kg}$, respectively. While these concentrations in the sand-covered area were $0.36 \mathrm{~g} / \mathrm{kg}, 6.23$ $\mathrm{mg} / \mathrm{kg}, 0.89 \mathrm{mg} / \mathrm{kg}, 2.88 \mathrm{~g} / \mathrm{kg}$, and $4.39 \mathrm{mg} / \mathrm{kg}$, respectively. According to China's second national soil survey standard ${ }^{20}$. All the available nitrogen ( $\mathrm{AN}, \mathrm{Ni}$ ) concentrations were at level 6 and all the TP concentrations were at level 1 for the three Pisha sandstone soils (Higher grades indicate lower 
concentrations and poorer soils). The concentration levels of TN and AP in bare Pisha sandstone soils were both level 5; The TN concentration level for soil covered Pisha sandstone soils was level 6 and the AP concentration level was level 4. The TN concentration level of the sand-covered Pisha sandstone soil was level 6 and the AP concentration level was level 5.

Therefore, it was clear from the above that there was no significant difference in the $\mathrm{N}$ and $\mathrm{P}$ nutrient profiles of the three Pisha sandstone soils, where the $\mathrm{N}$ concentration was extremely deficient and the $\mathrm{P}$ concentration was relatively abundant but the available components were lacking. That made it difficult for the local population to grow food crops in the traditional sense (corn, wheat) in the Pisha sandstone region. More people were choosing to grow buckwheat and sorghum, which are more tolerant of barrenness and drought. Based on the overall spatial distribution of $\mathrm{N}$ and $\mathrm{P}$ nutrients it appears that the soils of all three Pisha sandstones are extremely poor. Pisha sandstone soils have high infiltration rates and saturated hydraulic conductivity as well as mostly alkaline $\mathrm{pH}$ values (between 8.89 and 10.02), while natural precipitation has mostly acidic pH values (between 5.2 and 6.8) ${ }^{21}$. Therefore, the soil is susceptible to chemical reactions while being eroded by surface runoff generated by rainfall. During this erosion process, surface soils and soil nutrients are also continuously lost due to the action of runoff erosion. Local farmers planted economic fruit groves in areas with good soil and water conditions, but that didn't work to reduce surface runoff erosion and improve soil fertility. That' $s$ because most of the planting of economic fruit groves were done on the basis of destroying the native plant communities. The understory vegetation was even more devastatingly destroyed, with the process of surface cooked soil production severely affected, and the pathway for replenishing organic matter and $\mathrm{N}$ elements into the soil was basically cut off.

Soil erosion was further exacerbated by the lack of organic matter replenishment, soil consolidation and structural deterioration, making it more difficult for surface vegetation to survive. That is the main reason for the low soil fertility in the Pisha sandstone region ${ }^{22} ;{ }^{23}$. The effect of this on the local population was that more fertilizer had to be applied to the land in order to get the normal output in the farmland. About $90 \%$ of the fertilizer put into the soil was in the form of chemical fertilizer, although it rapidly replenished the $\mathrm{N}$ deficiency in the Pisha sandstone soil. But the consequence of heavy use of chemical fertilizers has been a deterioration of the soil structure and poor permeability of the slab. Erosion is more likely to occur when rainfall generates surface runoff, which causes the loss of $\mathrm{N}$ and $\mathrm{P}$ elements, resulting in surface source pollution and eventually returning to the vicious cycle of continued fertilizer application ${ }^{24 ;}{ }^{25}$. By accessing the local farmland, we found that the phenomenon of soil caking was common, and the local farmers could only solve it by manual loosening. This increases the labor cost which is the main reason for the indirect poverty of local farmers.

Large coefficients of variation (CV) of TN and TP of soils in the Pisha sandstone area were approximately $25.02 \%$ on average, while the coefficients of variation (CV) of available nutrients $\mathrm{AN}, \mathrm{Ni}$, and AP were relatively small averaged about $15.01 \%$. It was mainly due to the fact that the composition of TN and TP in soil nutrients is mainly influenced by the composition of the parent rock minerals that form the soil and most of them are present in the stable condition ${ }^{26}$. Although the sampling sites of different Pisha 
sandstone soils all belong to the Pisha sandstone area, the parent rock minerals (rock composition) of the Pisha sandstone forming soils are very complex, consisting of thickly bedded sandstones of Paleozoic Permian, Mesozoic Triassic, Jurassic and Cretaceous, mixed together to form a combined rock structure ${ }^{27}$. Therefore the degree of variation (CV) of TN and TP in the soil formed after its weathering and decomposition would be very significant $(p<0.05)$. The available nutrients $\mathrm{AN}, \mathrm{Ni}$, and AP in the soils of the Pisha Sandstone were closely related to the climatic conditions of the region, land use practices, decomposition of litter, and the forms of nutrient uptake and utilization by plants. More precisely, the available nutrients (AN, Ni and $\mathrm{AP}$ ) in the soil are more closely related to the agricultural and livestock production practices in the region. The inhabitants in this region are more likely to ensure output by heavy input of fertilizers and pesticides due to lack of knowledge about the nature of Pisha sandstone soil. The effective $\mathrm{N}$ and $\mathrm{P}$ content of the soil depends more on the residual fertilizer content after erosion by surface runoff (this effect was most pronounced at the top of the slope). That was one of the reasons for its relatively small coefficient of variation ${ }^{28,}{ }^{29}$.

\subsection{Status of soil TN and TP in different types of area}

Due to the concentration of precipitation in the Pisha sandstone region and the special complex geological conditions (combined form of sandstone). It has been formed by the interaction of wind and water erosion over a long period of time, forming a criss-crossing valley $21 ; 30 ; 31$. This leaves rocks of different properties exposed to the surface in turn. As a result, a landscape resembling a ribbon form pattern (different rock layers folded together) was formed on the slope face of the valley. Only at the top and bottom of the slope at the ends of the sub-basin section are there more (mature) soils, while on the slope surface the soils are very sparse that are mostly raw soils formed by direct weathering of the arsenic sandstone (lacking effective $\mathrm{N}$ and $\mathrm{P}$ for plant use). On slopes it is difficult to retain water and fertilizer due to the large slope(the slope was generally $40^{\circ}$ to $60^{\circ}$ degrees, with a maximum of $90^{\circ}$ ). The average concentration of TN and TP were mainly influenced by the parent material (rock composition) that formed the soil. The Pisha Sandstone is also a clastic rock with complex composition and obvious layering ${ }^{26}$.

Therefore, this results in a relatively large variation in TN and TP concentration despite being in the same Pisha sandstone area. For example, in the same Pisha sandstone area, there were significant differences $(p<0.05)$ in the TN and TP concentrations at different slope locations on the same cross-section. The TN and TP concentration levels at the top and bottom of the slope were significantly higher than those at other slopes. On the contrary, in different Pisha sandstone type areas, due to the same rock properties, the concentrations of TN and TP will tend to be at the same level with a larger number of samples. For example, the average TN concentration of the soil-covered Pisha sandstone was not significantly different from that of the sand-covered Pisha sandstone. There was no significant difference in the mean TP concentration of the soil between the bare Pisha sandstone compared to the soil-covered Pisha sandstone.

\subsection{Status of soil ANমNi and AP in different types of area}


Soil $\mathrm{N}$ is one of the most important essential elements that can be taken up by plants. AN and $\mathrm{Ni}$ are both available $\mathrm{N}$ in soil $\mathrm{N}$ elements that can be absorbed and used by plants. Although $\mathrm{AN}$ is partially affected by $\mathrm{TN}, 95 \%$ of available $\mathrm{N}$ in soil comes from the decomposition of organic matter in the soil ${ }^{28} ;{ }^{32}$. After studying the physicochemical properties of the soil after afforestation, it was found that the reserves of soil organic carbon (SOC), available nitrogen and phosphorus (AN, Ni, AP) in the sand-covered Pisha sandstone area increased significantly, it increased by $47.8-69.1 \%$ compared to the level of the soil on the surface without vegetation ${ }^{29}$. The reason why soil AN and $\mathrm{Ni}$ of bare Pisha sandstone were significantly higher than those of soil-covered Pisha sandstone and sand-covered Pisha sandstone was that soilcovered Pisha sandstone and sand-covered Pisha sandstone were subjected to certain anthropogenic disturbance and damage. For example, unreasonable farming, fuelwood cutting and grazing.

Our team's investigators found through extensive field visits and surveys that the current state of affairs was mainly composed of two reasons. Firstly, because the soil conditions of soil-covered Pisha sandstone was better than bare Pisha sandstone (the thickness of soil layer of soil-covered Pisha sandstone was more than $300 \%$ higher than bare Pisha sandstone). As a result, most of the production and living activities of local industry, mining and agriculture were concentrated here. Due to population pressure, the excessive intensity of agricultural and livestock production has put a great strain on soil fertility (including $\mathrm{AN}, \mathrm{Ni}, \mathrm{AP}$ ). In addition to the irrational use of natural resources by local residents. The effective $\mathrm{N}(\mathrm{AN}, \mathrm{Ni}$ ) of the soil cover Pisha sandstone (which originally has the highest soil fertility under natural conditions) becomes lower than that of the partially exposed Pisha sandstone region. The second was due to differences in the way the soil was replenished with water. Since no agricultural production activities would take place in the bare Pisha sandstone region, only drought-resistant native vegetation is present. That requires less water and basically relies on natural precipitation for recharge, which is very similar to sprinkler irrigation in agricultural irrigation. The soil cover Pisha sandstone demanded a great deal of water due to the large amount of agricultural activities to be carried out, especially during the filling period of the crop. When local people replenish their farmland with water, they mostly use diffused irrigation due to economic (lack of funds to purchase sprinkler equipment) and cognitive (no difference between sprinkler and diffuse irrigation) reasons, and only a few areas use sprinkler irrigation. The biggest impact of sprinkler and diffuse irrigation on the soil in the region was found through field visits to be the soil structure. Similarly planted buckwheat farmland, soil porosity using sprinkler irrigation for water replenishment could be more than $50 \%$ higher compared with diffuse irrigation. At the same soil moisture level, the increase in soil porosity greatly increased the activity of soil microorganisms and promoted the conversion rate of organic matter to effective $\mathrm{N}$ and $\mathrm{P}(\mathrm{AN}, \mathrm{Ni}, \mathrm{AP})$.

Wind and water erosion is more intense in the Pisha Sandstone area, and the accumulation of organic material on the surface is minimal, which severely amplifies the effects caused by anthropogenic damage. Meanwhile the vegetation cover of soil-covered Pisha sandstone and sand-covered Pisha sandstone was declining, exacerbating the rate of loss of available soil N (AN, Ni). Litter and livestock manure can increase the organic matter concentration of the soil, which in turn increases the available $\mathrm{N}$. However, the special climatic (high wind and low rainfall) and geographical conditions (high soil 
permeability) of the region inhibit the decomposition of litter and livestock manure, which further worsens the loss of available $\mathrm{N}$ elements (AN, Ni) from the soil (Gao et al., 2019).

Phosphorus as a relatively stable and poorly migrating sedimentary mineral, where the level of available phosphorus (AP) is mainly influenced by climatic environment, vegetation type and parent material forming the soil ${ }^{33} ;{ }^{34}$. The AP concentration in the soil-covered Pisha sandstone area was significantly higher than that in the bare Pisha sandstone and sand-covered Pisha sandstone $(p<0.05)$, which is due to the fact that AP is mainly composed of water-soluble phosphorus, partially adsorbed phosphorus and organic phosphorus. Water-soluble phosphorus is present in soil moisture and can be directly absorbed and used by plants, while adsorbed and organic phosphorus needs to be adsorbed in soil aggregates and cannot be free in soil moisture. So this good soil water-holding capacity and loose agglomerate structure is more adsorptive to AP. However, the soil water-holding capacity and agglomerate structure of the soilcovered Pisha sandstone are obviously better than those of the bare Pisha sandstone (less soil) and sand-covered Pisha sandstone (more gravel), which is the main reason for the higher AP concentration of the soil-covered Pisha sandstone.

The distribution patterns of available nutrients ( $\mathrm{AN}, \mathrm{Ni}, \mathrm{AP}$ ) of the soils were essentially the same characteristics at different slope locations in the three Pisha sandstone areas. The soil concentration levels of available nutrients ( $\mathrm{AN}, \mathrm{Ni}, \mathrm{AP}$ ) showed an overall decreasing trend from the top of the slope to the middle and bottom of the slope. It is mainly caused by severe soil erosion caused by heavy rainfall during the rainy season (July to September), resulting in serious soil loss and nutrient loss from the middle and lower surfaces of the slope. Due to the concentration of precipitation and the large relative height difference between the top and bottom of the slope (the maximum height difference in the study area exceeds $100 \mathrm{~m}$ ), it is difficult to form barriers because of the sparse vegetation on the slope near the bottom of the ditch. When runoff from rainfall collects at the bottom of the gully, the flow rate and ability to carry sediment are greatly enhanced, and the nutrient-rich topsoil deposits at the bottom of the slope are more susceptible to erosion. Therefore, in the middle, lower and bottom parts of the slope, there were few nutrient-rich topsoils and mostly immature subsoils. In addition, the soil of Pisha sandstone contains mostly sulfur trioxide and phosphorus pentoxide. These two substances are easily soluble in water and then produce harmful substances such as sulfuric acid and phosphoric acid, which acidify the soil at the bottom of the slope and reduce the biological activity, thus inhibiting the growth of vegetation. This was the main reason for the overall decline of $\mathrm{AN}, \mathrm{Ni}$, and $\mathrm{AP}$ from the top to the bottom of the slope observed in this study. And this result was consistent with the findings of Wang et al. who studied the slopes of the agro-pastoral transition zone on the Loess Plateau ${ }^{27}$. Liu et al studied the nutrient differences between topsoil $(0-30 \mathrm{~cm})$ and subsoil $(30-60 \mathrm{~cm})$ in the agro-pastoral ecological zone of northwest China and came to similar conclusions ${ }^{29}$. They found that topsoil was more abundant near the top of the slope, while soils in the middle, lower, and bottom parts of the gully were basically bare subsoil due to erosion.

Therefore, if the soil productivity of Pisha sandstone area is to be improved. On the one hand, it is necessary to increase the protection of existing natural vegetation, reduce negative human interference, prohibit indiscriminate cultivation and grazing, and select infertile-tolerant plants such as Hippophae 
rhamnoides Linn and Achnatherum splendens (Trin) Nevski according to local conditions to increase vegetation cover and thus reduce soil erosion. On the other hand, certain chemicals should be applied to improve the soil in areas where water tends to accumulate, such as at the bottom of ditches and slope bottoms, so that they can carry more plant growth and thus improve the ecological environment of the Pisha sandstone region. Meanwhile, with the drive of global climate change, the response mechanisms of $\mathrm{N}$ and $\mathrm{P}$ levels to soil moisture, slope and soil depth in each type of Pisha sandstone area need to be studied more systematically in the future, with a view to providing scientific basis and reference for the scientific evaluation of ecological restoration and management of different types of Pisha sandstone areas.

\section{Conclusions}

A trend of the average soil TN concentration level as follows: bare Pisha sandstone > sand-covered Pisha sandstone > soil-covered Pisha sandstone. However, there was no significant difference in soil TN concentration between sand-covered and soil-covered Pisha sandstone. A trend in the average concentration levels of $\mathrm{AN}$ and $\mathrm{Ni}$ in Pisha sandstone soils was as follows: bare Pisha sandstone > soilcovered Pisha sandstone $>$ sand-covered Pisha sandstone.

The trend of the average TP concentration levels in Pisha sandstone soils was the same as that of available nitrogen (AN, Ni), and the average AP concentration levels in Pisha sandstone soils were highest in soil-covered Pisha sandstone, followed by bare Pisha sandstone and sand-covered Pisha sandstone soils. Same trend was observed for the average concentrations of AN, Ni and AP in soils of the same type of Pisha sandstone region, with higher concentrations near the top of the slope and lower concentrations near the bottom of the slope. This indicates that the concentration levels of AN, Ni and AP in Pisha sandstone soils were significantly influenced by the location of the slope.

\section{Declarations}

\section{Acknowledgements}

This study was financially supported by the Fundamental Research Funds for the State Key Research and Development Program of China "comprehensive treatment technology for composite soil erosion in the Pisha sandstone area" (2017YFC0504503). We would like to thank the Beijing Forestry University School of Soil and Water Conservation for the support for the Project. The local farmers also provided additional assistance during the collection of our experimental samples.

\section{Conflict of Interest}

The authors declare no conflict of interest.

\section{References}


1. Zhao, G., Mu, X., Wen, Z., Wang, F. \& Gao, P. Soil Erosion, Conservation, and Eco-Environment Changes in the Loess Plateau of China. Land Degrad. Dev. 24, 499-510 (2013).

2. Shi, Y., Ye, H., Hou, H. \& Bi, Z. The Internal Cause of the Erosion in 'Pisha' Sandstone Area, Southern Inner Mongolia. Acta Geoscientica Sinical. 659-664 (2004).

3. Zhang, P., Liu, Y. \& Zhang, Z. The Features of Sediment Production and the Analysis of Genesis by Erosion in Hunagfuchuan Watershed. Bulletin of Soil and Water Conservation. 15-24 (1992).

4. Yang, L., Xie, Z., Qin, Y. \& Sun, Y. Temporal-Spatial Variation Characteristics of Soil Erosion in the Pisha Sandstone Area, Loess Plateau, China. Pol. J. Environ. Stud. 28, (2019).

5. Wang, H., Huang, C. L., Yang, F. S. \& Huai-En, L. I. Root Habitat Flexibility of Seabuckthorn in the Pisha Sandstone Area. Chinese Journal of Applied Ecology. (2019).

6. Yang, F. et al. Simulation of Sediment Retention Effects of the Double Seabuckthorn Plant Flexible Dams in the Pisha Sandstone Area of China. Ecol. Eng. 2014,71, 21-31 (2014).

7. Wang, Y. et al. Definition of Arsenic Rock Zone Borderline and its Classification. Science of Soil and Water Conservation. 5, 14-18 (2007).

8. Fan, C., Miao, W. U., Rui, S. U., Zhang, Z. \& Hong, H. E. Effects of Pisha Sandstone-Amended Aeolian Sandy Soil On Growth, Nitrogen and Phosphorus Nutrition of Two Introduced Plants. J. Soil Water Conserv. (2019).

9. Wang, L., Li, C. \& Dong, J. Study On Distribution and Lithologic Characters of Feldspathic Sandstone. Yellow River. (2013).

10. Begonha, A. \& Braga, M. Weathering of the Oporto Granite: Geotechnical and Physical Properties. Catena. 49, 57-76 (2002).

11. Li, Y., Xie, Z. X., Qin, Y. C. \& Sun, Y. Y. Temporal-Spatial Variation Characteristics of Soil Erosion in the Pisha Sandstone Area, Loess Plateau, China. Pol. J. Environ. Stud. 004, 103-109 (2019).

12. Shi, Y., Ye, H., Shi, J., Yu, J. \& Hou, H. Remote Sesing Survey of Edge Line Changes and Analysis of Affecting Factors in Pisha Sandstone Area. Remote Sensing for Land \& Resources. 59-64 (2009).

13. Tang, Z., Cai, G., Li, Z. \& ZHao, H. Study On Interaction Among Wind Erosion, Hydraulic Erosion and Gravity Erosion in Sediment-Rock Region of Inner Mongolia. J. Soil Water Conserv. 25-29 (2001).

14. Wang, J. Analysis On Sediment Reduction Effect of Seabuckthorn Ecological Project in Yellow River Coarse Sediment Concentration Area. Soil and water conservation in China. 86-88 (2016).

15. Wu, Y., Hu, J., Min, X., Liu, X. \& Zuo, T. Reduction Effects of Flood and Sediment Yield of Hippophae Rhamnoides Linn Forest in Soft Sandstone Area. Science of Soil and Water Conservation. 9, 68-73 (2011).

16. Zhang, H., Wang, H. \& Sun, Y. Relationship Between Soil Origanic Matter and Total Nitrogen in Compound Soil of Arsenic Sandstone and Sand with Number of Maize Cultivation Years in Mu Us Sand Land

17. . Bulletin of Soil and Water Conservation. 39, 242-245 (2019). 
18. Yuan, Q., Cui, X. X. \& Qiao, R. Effect of Different Artificial Forest Plantations On Soil Physical and Chemical Properties of Sandstone Areas. Northern Horticulture. 18, 52-55 (2013).

19. He, N., Yu, Q., Wu, L., Wang, Y. \& Han, X. Carbon and Nitrogen Store and Storage Potential as Affected by Land-Use in a Leymus Chinensis Grassland of Northern China. Soil Biology and Biochemistry. 40, 2952-2959 (2008).

20. Bao, S. D. Soil and Agricultural Chemistry Analysis, Chinese Agriculture Press (Beijing, 2000).

21. Office, N. S. C. Soil Survey Technology in China, Agriculture Press, 1992).

22. Ma, W. \& Zhang, X. Effect of Pisha Sandstone On Water Infiltration of Different Soils On the Chinese Loess Plateau. J. Arid Land. 8, 331-340 (2016).

23. Liang, Z. et al. Effects of Rainfall Intensity, Slope Angle, and Vegetation Coverage On the Erosion Characteristics of Pisha Sandstone Slopes Under Simulated Rainfall Conditions. Environ. Sci. Pollut. R. 27, 17458-17467 (2020).

24. Tamene, L. et al. Soil Structural Degradation and Nutrient Limitations Across Land Use Categories and Climatic Zones in Southern Africa. Land Degrad. Dev. (2019).

25. Liu, H. et al. Temporal and Spatial Characteristics and Influencing Factors of Nitrogen Morphology in Surface Sediments of Liangtan River,Chongqing. J. Soil Water Conserv. 6, 332-341 (2019).

26. Pan, C., Li, L. \& Zhang, H. Spatio-Temporal Variations and Source Apportionment of Water Pollution in Danjiangkou Reservoir Basin, Central China. Water-Sui. 7, 2591-2611 (2015).

27. Bouraima, A. K., He, B. \& Tian, T. Runoff, Nitrogen (N) and Phosphorus (P) Losses From Purple Slope Cropland Soil Under Rating Fertilization in Three Gorges Region. Environmental Science \& Pollution Research. 23, 4541-4550 (2016).

28. Wang, L. H., Qiu, L. P., Gao, H. L. \& Zhang, X. C. Phosphorous Distribution of Plant-Soil System in a Stipa Bungeana Slope Land in the Agro-Pastoral Transitional Zone. Journal of Plant Nutrition and Fertilizer. 5, 1192-1199 (2013).

29. Gao, J., Luo, F. \& Gao, Y. Ecological Soil C, N, and P Stoichiometry of Different Land Use Patterns in the Agriculture-Pasture Ecotone of Northern China. Acta Ecologica Sinica. 39, 1-9 (2019).

30. Liu, X., Li, L., Wang, Q. \& Mu, S. Land-Use Change Affects Stocks and Stoichiometric Ratios of Soil Carbon, Nitrogen, and Phosphorus in a Typical Agro-Pastoral Region of Northwest China. J. Soil. Sediment. 11, 3167-3176 (2018).

31. Liu, H., Shi, M., Cai, H. \& Wu, Y. Experimental Study of the Physical Characteristics of the Pisha Sandstone On its Erosion. Yellow River. 38, 8-10 (2016).

32. Zhang, C., Qin, F., Wang, H., Li, N. \& Yang, L. Quantization and Spatial Variation of Topographic Features Using 3D Fractal Dimensions in Arsenic Rock Area. Scientia Geographica Sinica. (2016).

33. Palviainen, M. et al. Release of Potassium, Calcium, Iron and Aluminium From Norway Spruce, Scots Pine and Silver Birch Logging Residues. Plant Soil. 259, 123-136 (2004).

34. Kooijman, A. M., Jongejans, J. \& Sevink, J. Parent Material Effects On Mediterranean Woodland Ecosystems in Ne Spain. Catena. 59, 55-68 (2005). 
35. Zeng, Q. C., Xin, L. I., Dong, Y. H. \& Shao-Shan, A. N. Ecological Stoichiometry of Soils in the Yanhe Watershed in the Loess Plateau:the Influence of Different Vegetation Zones. Journal of Natural Resources. 11, 91-101 (2016).

\section{Figures}
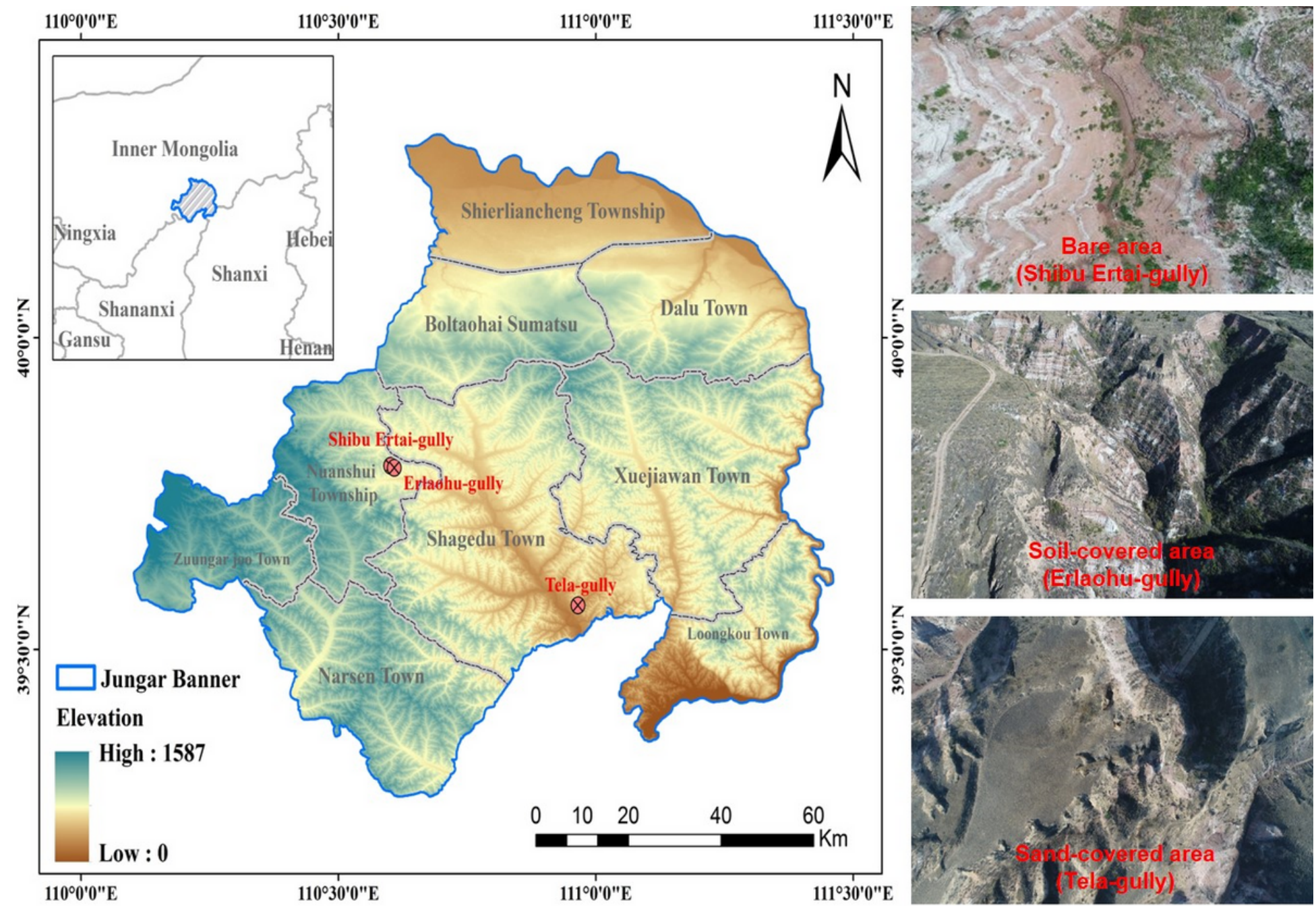

Figure 1

Location of the study area. 


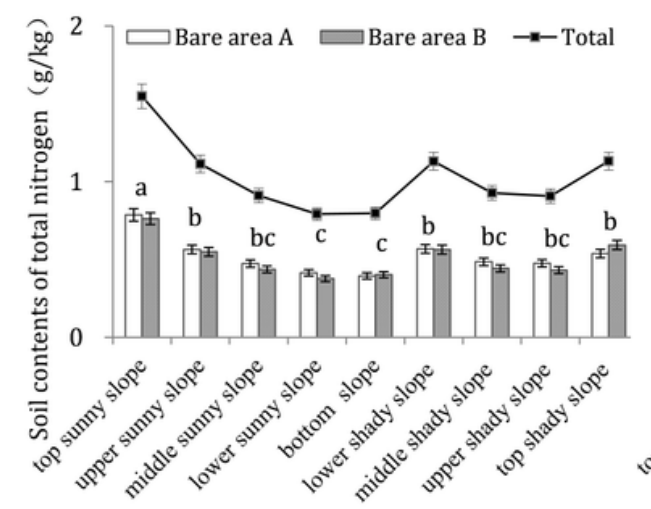

different slope positions and directions

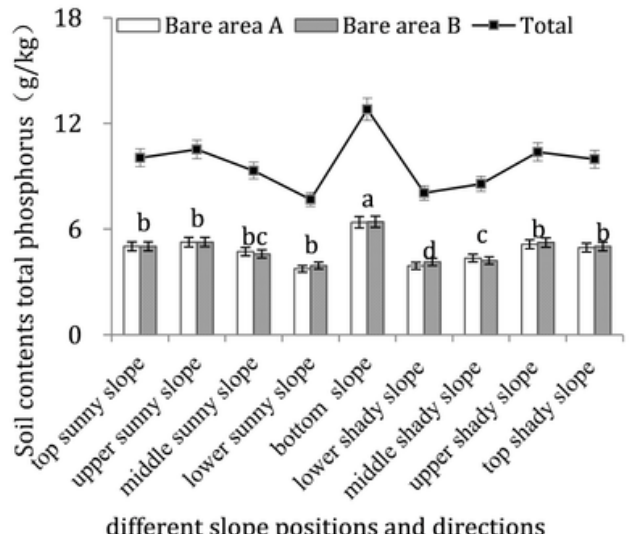

different slope positions and directions

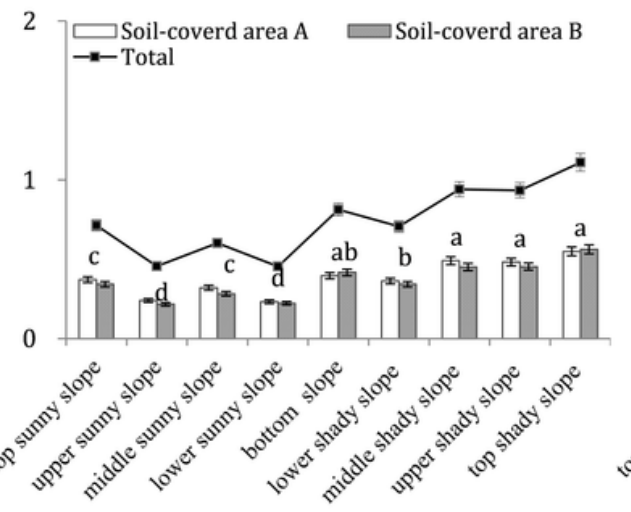

different slope positions and directions

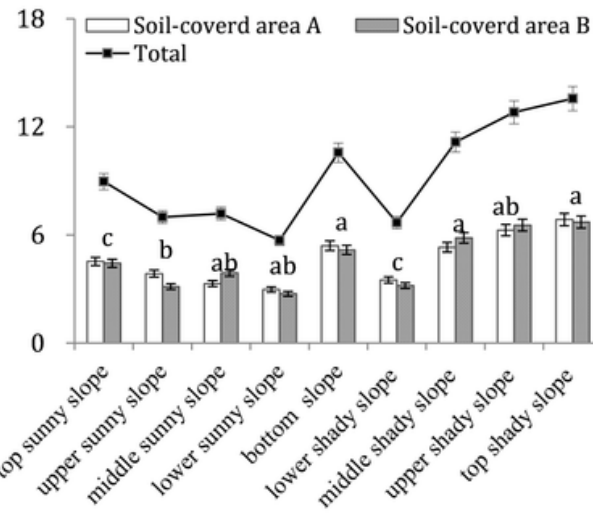

different slope positions and directions
$2 \square$ Sand-coverd area A $\square$ Sand-coverd area B $\because-$ Total

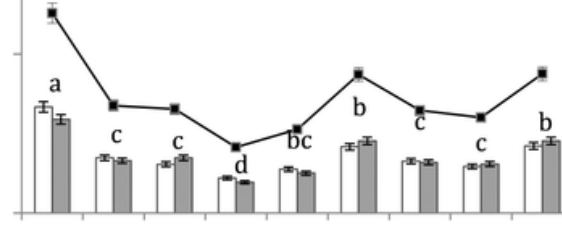

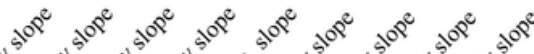

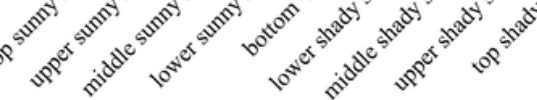

different slope positions and directions

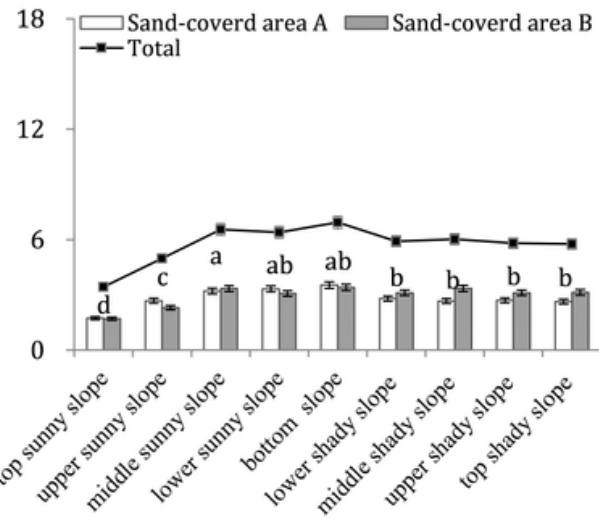

different slope positions and directions

Figure 2

Soil concentrations of total nitrogen (TN) and total phosphorus (TP) in different types of areas. Note: A and $B$ represent soil taken from depths of $0-10 \mathrm{~cm}$ and $10-20 \mathrm{~cm}$, respectively. Different lowercase letters indicate significant differences in TN and TP concentrations between different slope positions and slope directions $(\mathrm{p}<0.05)$. The same applies in Figs $3-4$ below. 


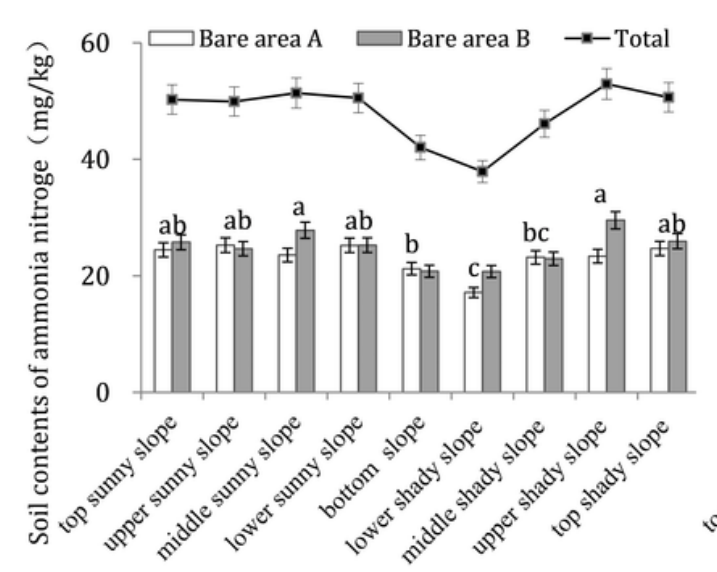

different slope positions and directions

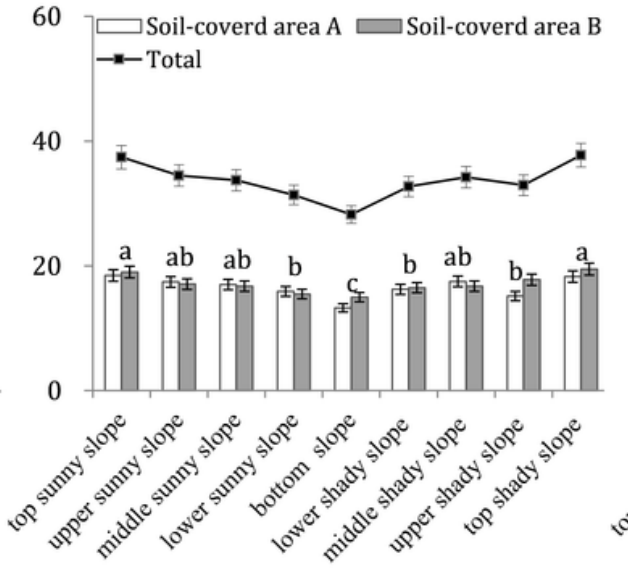

different slope positions and directions $60\rceil$ Sand-coverd area A $\square$ Sand-coverd area B $\rightarrow-$ Total
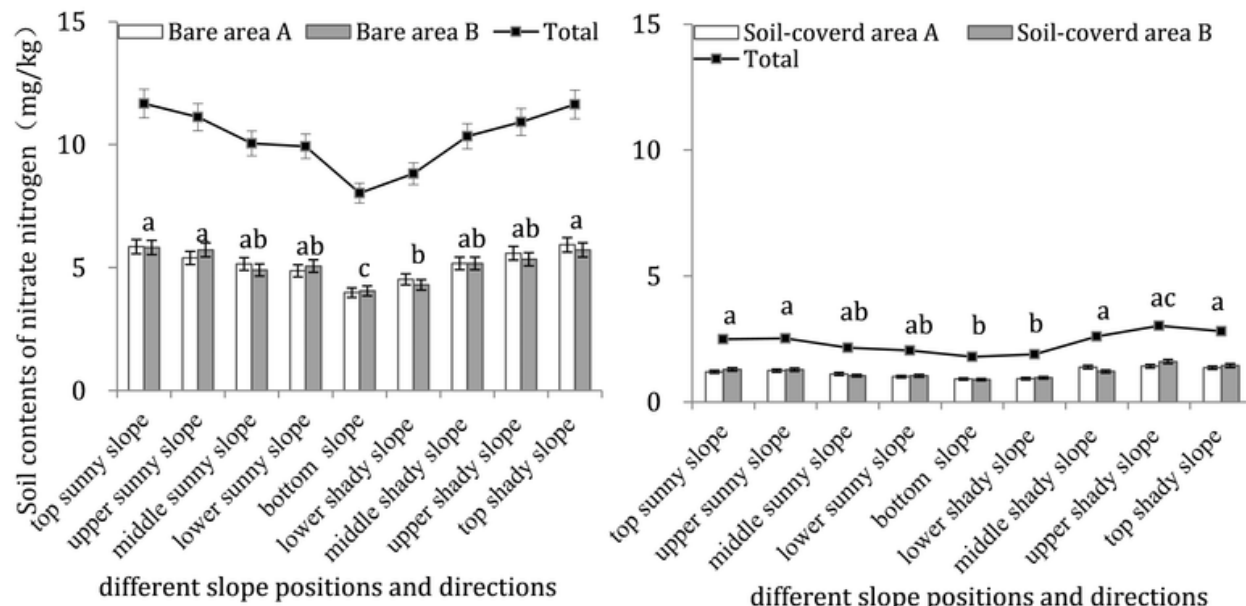

$15 \square$ Sand-coverd area A $\square$ Sand-coverd area B

$\rightarrow-$ Total

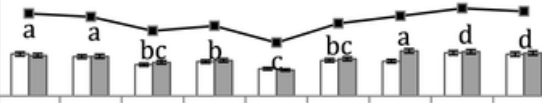

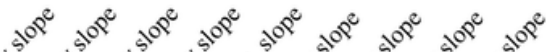

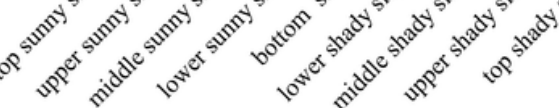

different slope positions and directions

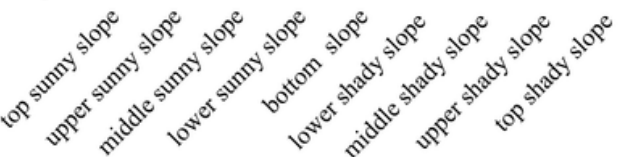

different slope positions and directions
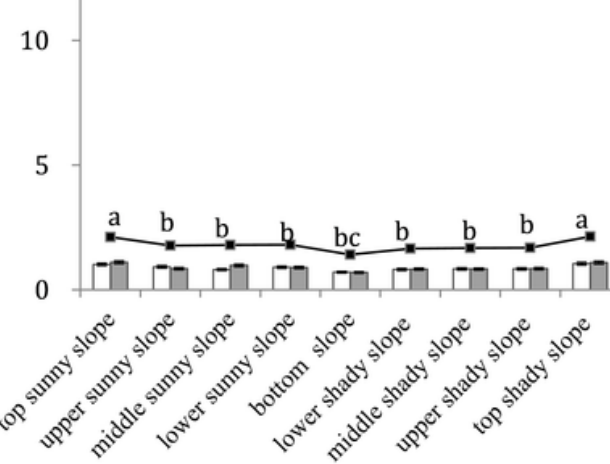

different slope positions and directions

\section{Figure 3}

Soil effective nitrogen (AN, Ni) concentrations in different types of Pisha sandstone.

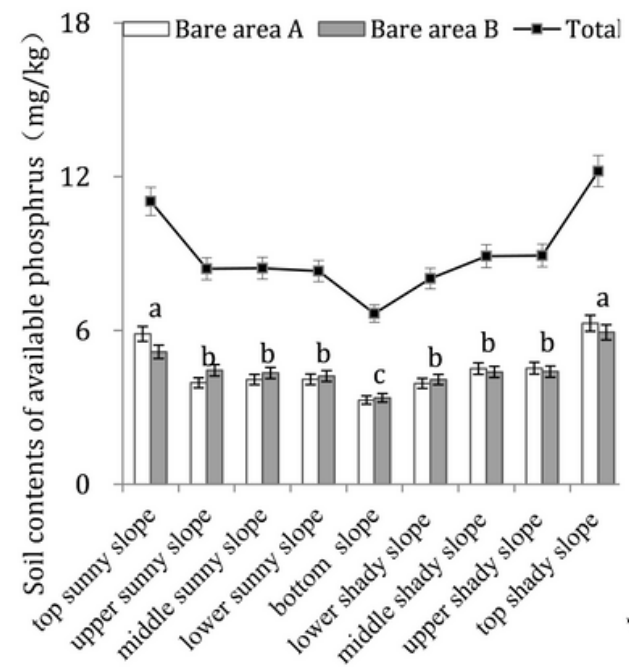

different slope positions and directions

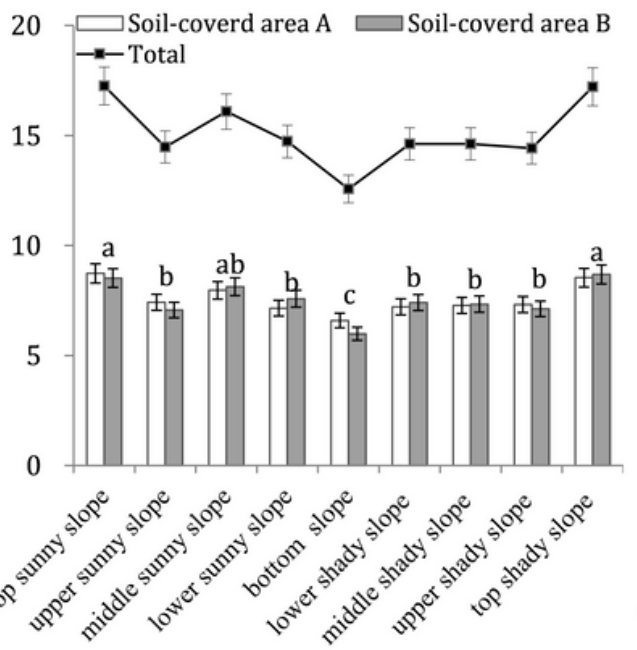

different slope positions and directions

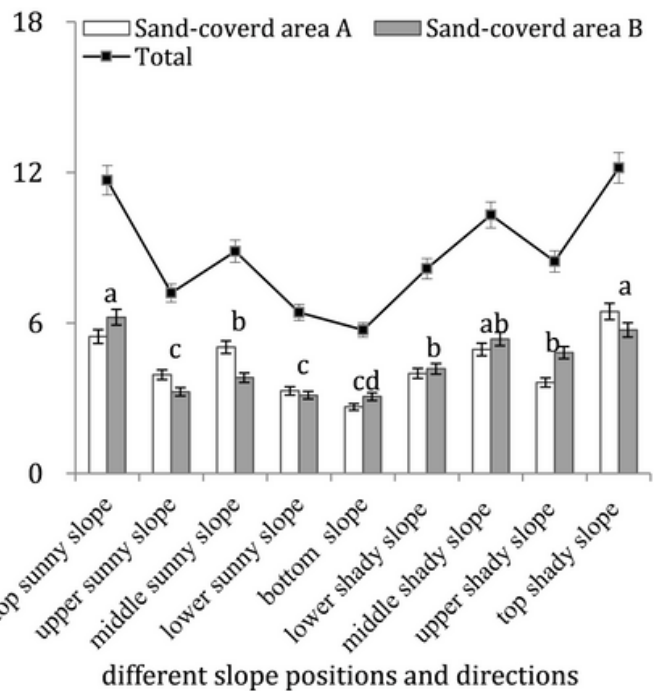

Figure 4 
Soil concentrations of available phosphorus (AP) in different types of area. 